\title{
TRV Rating Concepts and Generation of TRV Envelopes for Synthetic Testing of Extra High Voltage Circuit Breakers
}

\author{
6J. G. Jamnani, IEEE Member and Mrs. S.A. Kanitkar
}

\begin{abstract}
Development in electrical power transmission system requires the use of circuit breakers with increasing breaking capacity. At present circuit breakers are to be installed on $245 \mathrm{kV}$ to $1200 \mathrm{kV}$ power system with short circuit ratings up to $120 \mathrm{kA}$. To test high voltage $\mathrm{CBs}$, direct testing using the power system or short circuit alternators are not feasible. The testing of high voltage CBs of larger capacity requires very large capacity of testing station. To increase testing plant power is neither an economical nor a very practical solution. Synthetic testing is an alternative equivalent method for testing of high voltage circuit breakers and is accepted by the standards. This paper presents a TRV rating concepts, IEC standards TRV envelopes and types of synthetic test circuits and their comparison. Analysis and mathematical modeling of 4-parameters TRV synthetic test circuit is done. A 4parameters TRV synthetic test circuit based on parallel current injection method is designed and simulated for testing $420 \mathrm{kV}$ and $800 \mathrm{kV}$ rating circuit-breakers as per new TRV requirements given in IEC 62271-100(2008).
\end{abstract}

Index Terms - A.C. high voltage circuit breakers, Direct testing, Synthetic tests, TRV circuits, Terminal and Shortline faults.

\section{INTRODUCTION}

In Synthetic testing, there are two sources of power supply for the testing

(i) Current source (ii) Voltage source

The current source is a high current, low voltage source. It supplies short circuit current during the test. The voltage source is a high voltage low current source. It provides transient recovery voltage.

The largest test facility in the world, KEMA high power laboratory, with a maximum short-circuit power of $8400 \mathrm{MVA}$ and a $145 \mathrm{kV}, 31.5 \mathrm{kA}, 3$-phase direct test capability, is limited in its power to perform the direct tests. At the present time a complete pole of $\mathrm{SF}_{6}$ circuit-breaker can consist of a single interrupting chamber with an interrupting power above the 10GVA level. Even KEMA'S high power laboratory can not verify the short-circuit interrupting capability by direct test methods[11],[13].

The unit testing method is used in laboratory to test

J. G. Jamnani is with the Department of Electrical Engineering, Institute of Technology, Nirma University, Ahmedabad, India. (email: jg.jamnani@nirmauni.ac.in)

Mrs. S. A. Kanitkar is with the Department of Electrical Engineering, Faculty of Technology and Engineering, M.S.University, Baroda, India. (Email: smitakanitkar@yahoo.com).
Extra and ultra high voltage circuit-breakers at present. With this method, interrupting units are tested at a part of rated voltage of the complete breaker. This method is recognized by the IEC standard, but one major problem remains, namely the influence of the post-arc conductivity on the voltage distribution across the units. The trend of increasing the interrupting capability of a single interrupting unit will result in it being impossible to test a single unit in the high power laboratory[13].

\section{TyPES OF SyNTHETIC TEST CIRCUITS AND COMPARISON}

Several synthetic testing methods have been developed and their performances have been studied in the past forty years[2],[4],[5]. If the source of energy during the interaction interval is used to classify the methods adopted, they can be distinguished by two basic methods:

(i) Current injection and (ii) Voltage injection method.

Depending on whether voltage circuit or source is switched on before or after current zero, the type of synthetic testing is known as current injection or voltage injection respectively.

Further the current injection method can be classified as parallel current injection and series current injection method. In parallel current injection method, the voltage circuit is inserted in parallel with the test breaker, while in series current injection method, it is inserted in series. The parallel current injection type synthetic testing is popular in Germany and is known as Weil - Dobke circuit. The series current injection type synthetic test circuit was suggested by Koplan Bashatyr (U.S.S.R) and is known as Russian circuit. In voltage injection method, the voltage source is switched on after the current zero. This method was suggested by Siemens, Germany.

More than forty years of synthetic testing experience shows that the current injection method has better equivalence than the voltage injection method. To produce four-parameter TRV, several TRV circuits have been developed but parallel current injection method with a Weil-Dobke TRV control circuit is the most popular used synthetic testing circuit in the high power laboratories as it is capable of providing RRRV and recovery voltage as required by various standards. Weil-Dobke circuit has a low capacity requirement on 
the main capacitor bank as compared to other TRV control circuits and is easy to design the various components. However, special attention should be paid on the insulation coordination of TRV branches [10-14].

\section{TRV RATING CONCEPTS AND IEC STANDARDS TRV ENVELOPES}

As per IEC 62271-100, the rated characteristics of a circuit breaker include rated transient recovery voltage for terminal faults as well as short line fault condition.

The terminal fault is defined as a fault occurring very near to the terminal of the circuit breaker and that the reactance between the fault point and breaker is negligible. Under this condition, the fault or short circuit current depends upon the source voltage and source impedance, as the impedance between the breaker and the fault is negligible.

The faults occurring between a distance of a few $\mathrm{km}$ to a few tens $\mathrm{km}$ from the circuit breaker are called the short line or kilometric faults. Such faults are characterized by high frequency of restriking voltage of the order of 10 to $100 \mathrm{kHz}$ depending upon the line length and fault location. The resulting TRV for short line fault appearing across $\mathrm{CB}$ pole is the vector sum of the voltage from the source and the line side.

Short circuit tests on High voltage circuit-breakers require circuit with response specified by IEC standards represented by either Fig.1 or Fig.2. IEC standards define two TRV envelopes [1], [3].

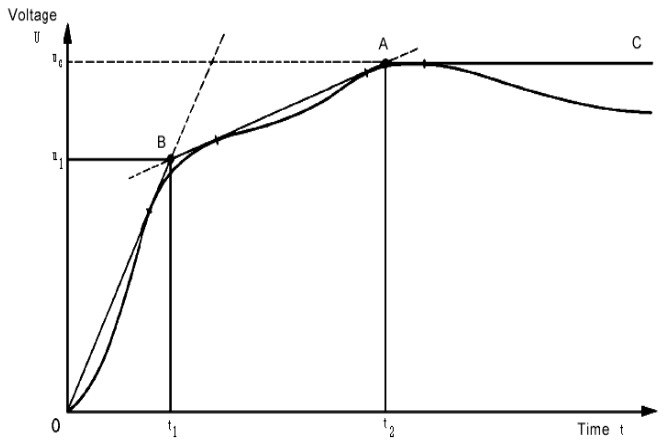

Fig.1. Representation by four parameters $\left(u_{1}\right.$ and $t_{1}, u_{c}$ and $\left.t_{2}\right)$ of a prospective transient recovery voltage of a circuit, case-1

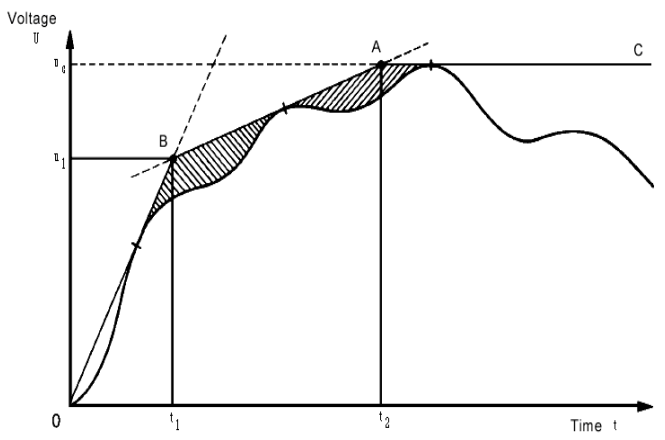

Fig.2. Representation by four parameters $\left(\mathrm{u}_{1}\right.$ and $\mathrm{t}_{1}, \mathrm{u}_{\mathrm{c}}$ and $\left.\mathrm{t}_{2}\right)$ of $\mathrm{a}$ prospective transient recovery voltage of a circuit case-2

\section{A. Case of two parameters}

For circuit breakers rated less than $100 \mathrm{kV}$, the envelope is defined by the two parameter method.

$\mathrm{u}_{\mathrm{c}}=$ reference voltage (TRV peak value) in $\mathrm{kV}$;

$\mathrm{t}_{3}=$ time to reach $\mathrm{u}_{\mathrm{c}}$ in microseconds.

\section{B. Case of four parameters}

For circuit breakers rated $100 \mathrm{kV}$ and above, the TRV envelope is defined by the four-parameter method represented by either Fig. 1 or Fig. 2.

$\mathrm{u}_{1}=$ first reference voltage, in $\mathrm{kV}$,

$\mathrm{t}_{1}=$ time to reach $\mathrm{u}_{1}$, in microseconds

$\mathrm{u}_{\mathrm{c}}=$ second reference voltage(TRV peak value), in $\mathrm{kV}$

$\mathrm{t}_{2}=$ time to reach $\mathrm{u}_{\mathrm{c}}$ in microseconds.

TRV parameters are defined as a function of the rated voltage $\left(\mathrm{U}_{\mathrm{r}}\right)$, the first-pole-to-clear factor $\left(\mathrm{k}_{\mathrm{pp}}\right)$ and the amplitude factor $\left(\mathrm{k}_{\mathrm{af}}\right)$ as follows:

$$
\mathrm{u}_{1}=0.75 \mathrm{x}\left(\mathrm{k}_{\mathrm{pp}}\right) \times \mathrm{U}_{\mathrm{r}} \sqrt{\frac{2}{3}}
$$

$t_{1}$ is derived from $u_{1}$ and the specified value of the rate of rise $u_{1} / t_{1}=R R R V$.

$t_{2}=4 t_{1}$ for terminal fault and short line fault;

For rated voltages equal or higher than $100 \mathrm{kV}$, the time delay $t_{d}=2 \mu$ s for terminal fault and short line fault;

$$
\mathrm{u}_{\mathrm{c}}=\mathrm{k}_{\mathrm{af}} \times \mathrm{k}_{\mathrm{pp}} \times \mathrm{U}_{\mathrm{r}} \sqrt{\frac{2}{3}},
$$

Where $\mathrm{k}_{\mathrm{af}}=1.4$ for terminal and short line fault; $\mathrm{k}_{\mathrm{pp}}=1.3$ for terminal fault

$=1.0$ for short line fault

IV. AnAlysis And Mathematical Modeling of 4 PARAMETERS TRV Synthetic TeSt CiRCUIT

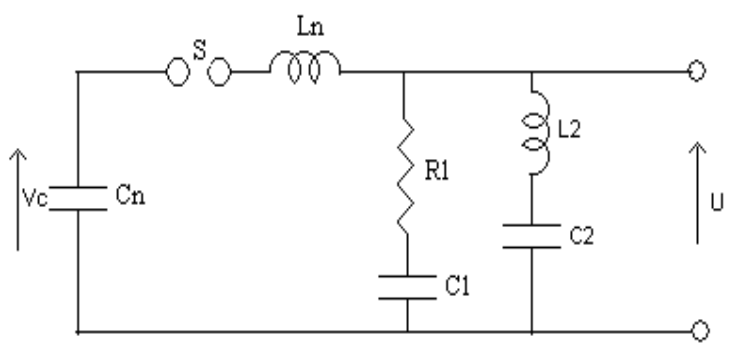

Fig.3. Multi Frequency Circuit

The circuit shown in Fig.3 permits to produce 4- parameters transient recovery voltages (TRV) according to IEC standards. $\mathrm{Vc}$ is the charging voltage. $\mathrm{Cn}, \mathrm{C} 1, \mathrm{C} 2$, Ln, L2 and R1 are the circuit components. The magnitude and the frequency of the transient recovery voltage depend on the voltage to which the capacitor $\mathrm{Cn}$ is charged and the values of circuit components. $u$ is the transient recovery voltage. $\mathrm{C} 1, \mathrm{C} 2, \mathrm{Ln}, \mathrm{L} 2$ and $\mathrm{R} 1$ are to control TRV and RRRV.

The expression for the transient recovery voltage is as follows:

$$
\begin{aligned}
u(s)=-\frac{C n V c}{s} & \cdot \frac{(1+s R 1 C 1)\left(1+s^{2} L 2 C 2\right)}{s^{4} L n C n L 2 C 2 C 1+s^{3} R 1 C n C 1 C 2(L n+L 2)+s^{2}[L n C n(C 1+C 2)+L 2 C 2(C n+C 1)]} \\
& +s R 1 C 1(C n+C 2)+C n+C 1+C 2
\end{aligned}
$$

The time expression of the recovery voltage is complex, but by making some hypotheses, it is possible to obtain some fundamental information concerning the TRV generated by this configuration[9]. Indeed, a simple 
analysis of the position of the poles of the above mentioned expression reveals the existence of 2 frequencies:

\section{A. Low Frequency circuit}

The low frequency voltage wave corresponds to the natural oscillation of the circuit represented by Fig.4. This low frequency circuit consists of circuit components $\mathrm{Cn}, \mathrm{C} 2, \mathrm{Ln}$ and $\mathrm{L} 2$.

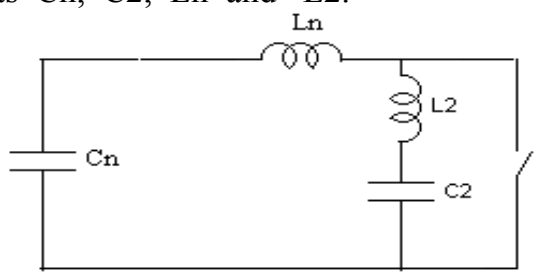

Fig.4. Low frequency circuit

Low frequency

$$
\begin{aligned}
f n_{2} & =\frac{1}{2 \pi \sqrt{(L n+L 2) \cdot \frac{C n \times C 2}{C n+C 2}}} \\
\therefore t_{m 2} & =\frac{10^{3}}{2 \times f n_{2}}
\end{aligned}
$$

Where

$f n_{2}=$ low frequency oscillation of the voltage wave, in $\mathrm{kHz}$

$t_{m 2}=$ time to reach peak of low frequency voltage wave, in $\mu$ s

B. High Frequency circuit

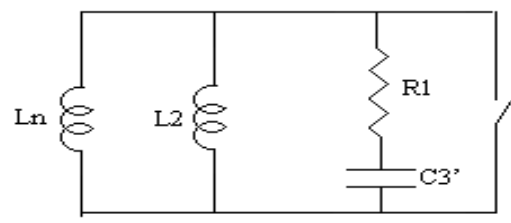

Fig.5. High frequency circuit

The high frequency voltage wave arises from the free oscillation of the circuit shown in Fig.5. The value of high frequency depends upon the circuit components C3, Ln and L2.

$$
\begin{gathered}
C 3^{\prime}=C 1 \times \frac{C n+C 2}{C n+C 1+C 2} \\
L e q=L n \amalg L 2=\frac{L n \times L 2}{L n+L 2} \\
f n_{1}=\frac{1}{2 \pi \sqrt{L e q \times C 3^{\prime}}} \\
t_{m 1}=\frac{10^{3}}{2 \times f n_{1}}
\end{gathered}
$$

Where

$f n_{1}=$ high frequency oscillation of the voltage wave, $\mathrm{kHz}$

$t_{m 1}=$ time to reach peak of high frequency voltage wave, $\mu \mathrm{s}$.

The TRV can then be considered as a result of the oscillations of both low frequency and high frequency circuits.

\section{PROGRAM/SOFTWARE DEVELOPMENT FOR FINDING CIRCUIT COMPONENTS}

The parameters of TRV defined by IEC standards are quite impossible to analytically link with the values of the components of the test circuit. So computer aided design and simulation of synthetic testing circuits (TRV shaping circuits) is first necessary in order to determine the parameters of the TRV corresponding to a given test circuit. In order to find the possible combinations of circuit components and to optimize the values of capacitance of capacitor banks for the desired frequencies $\mathrm{tm}_{1}$ and $\mathrm{tm}_{2}$ of a particular rating of circuitbreaker, program has been developed by using MATLAB M-file. Design optimization is done to reduce the values of capacitance of capacitor banks and hence reduce the energy required, size and cost of the capacitor banks.

Program/software is also developed with the help of VISUAL BASIC 6 software to find all possible combinations of the circuit components and also to optimize the circuit components for the desired frequencies $\mathrm{tm}_{1}$ and $\mathrm{tm}_{2}$ for a particular rating of circuit-breaker. This software is user friendly and speed is very fast, just by one click it will show all the possible combinations of circuit components for the desired frequencies. The algorithm to find optimized circuit components is given below:

\section{Algorithm}

Objective Function: Minimize( optimize) the value of capacitance of Capacitor Banks $\mathrm{Cn}, \mathrm{C} 1$ and $\mathrm{C} 2$ for a desired frequencies (for the same test conditions) as per IEC for a particular rating of circuit-breaker.

- Enter the desired frequencies $\left(\mathrm{tm}_{1}\right.$ and $\left.\mathrm{tm}_{2}\right)$ for a particular rating of circuit-breaker

- Specify the maximum and minimum values of the following independent variables or circuit components:

Main Capacitor Bank: Cn

TRV Capacitor Banks: $\mathrm{C}_{1}$ and $\mathrm{C}_{2}$

Reactors: $\mathrm{Ln}$ and $\mathrm{L}_{2}$

- calculate all possible combinations of circuit components for the desired frequencies

- The values of TRV Capacitor Banks can be determined by using the following equations:

$$
\begin{aligned}
& C_{1}=\frac{\left(C n+C_{2}\right)}{4 \pi^{2} f n_{1}{ }^{2} \operatorname{Leq}\left(C n+C_{2}\right)-1} \\
& C_{2}=\frac{C n}{4 \pi^{2} f n_{2}{ }^{2}\left(L n+L_{2}\right) C n-1}
\end{aligned}
$$

- $\quad$ Find the optimal values of capacitor banks $\mathrm{Cn}, \mathrm{C}_{1}$ and $\mathrm{C}_{2}$.

The developed program/software is tested for finding all possible and optimized circuit components to test $420 \mathrm{kV}$ rating circuit-breakers for terminal as well as short line fault test duty condition according to IEC standards. The suitable and optimized circuit components obtained is shown in Table I. 
TABLEI

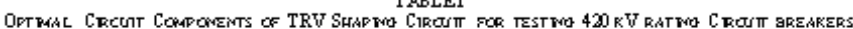
(WTH THE TRV COWTROL CECUIT SHOWN W FW. 6

\begin{tabular}{|c|c|c|c|c|}
\hline $\begin{array}{l}\text { Raing af } \\
\text { CB }\end{array}$ & Circuit components & \multicolumn{2}{|c|}{$\begin{array}{l}\text { Temind Fault } \\
\text { Tert Duryy }\end{array}$} & \\
\hline \multirow{5}{*}{$420 \mathrm{kV}$} & & Aspercase-I & As per & $\frac{\text { Ies Ding }}{\text { Aspercase-I }}$ \\
\hline & $\begin{array}{ll}\text { Capacitor Banks } \\
\text { Main Capacitor Bark: } \\
\text { TRV Capacitor Bark: } & \mathrm{C}_{n} \\
& \mathrm{C}_{1} \\
\text { Stroy capactar Bark: } & \mathrm{C}_{1}\end{array}$ & $\begin{array}{l}32 \mu \mathrm{F} \\
0.6 \mu \mathrm{F} \\
1.4 \mu \mathrm{F} \\
21 \mathrm{rF}\end{array}$ & $\begin{array}{l}32 \mu \mathrm{F} \\
05 \mu \mathrm{F} \\
2 S \mu \mathrm{F} \\
2 \operatorname{lnF}\end{array}$ & $\begin{array}{l}32 \mu F \\
0 S \mu F \\
1 S \mu F \\
21 \mu F\end{array}$ \\
\hline & $\begin{array}{c}\mathrm{L}_{\mathrm{n}} \\
\mathrm{L}_{\mathbf{n}} \\
\mathrm{L}_{2}\end{array}$ & $\begin{array}{c}19 \mathrm{mH} \\
100 \mathrm{mH} \\
17 \mathrm{mH}\end{array}$ & $\begin{array}{c}18 \mathrm{mH} \\
100 \mathrm{mH} \\
9 \mathrm{mH}\end{array}$ & $\begin{array}{c}13 \mathrm{mH} \\
100 \mathrm{mH} \\
11 \mathrm{mH}\end{array}$ \\
\hline & Reistors: & $\begin{array}{l}32 \Omega \\
20 \Omega\end{array}$ & $\begin{array}{l}16 \Omega \\
10 \Omega\end{array}$ & $\begin{array}{l}25 \Omega \\
15 \Omega\end{array}$ \\
\hline & Charging Voltage, $v_{c}$ & \multicolumn{2}{|c|}{$424 \mathrm{kV}$} & $320 \mathrm{kV}$ \\
\hline
\end{tabular}

VI. DESIGN AND Simulation OF $4-$ PARAMETERS TRV PARALLEL CURRENT INJECTION SyNTHETIC TEST CiRCUIT

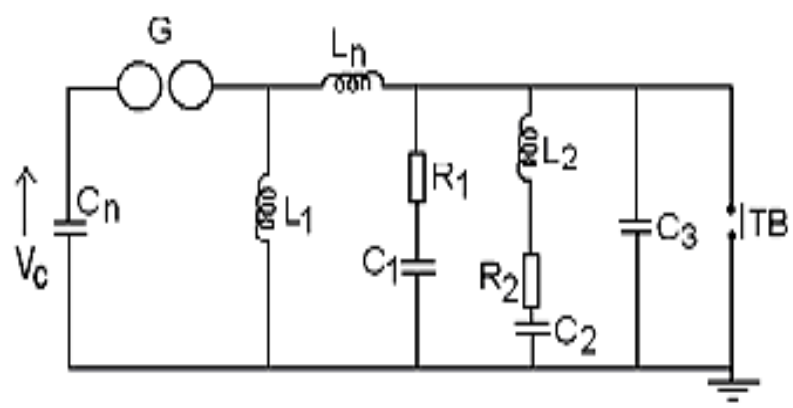

Fig.6. 4 -Parameters TRV parallel current injection synthetic testing circuit (Control circuit-I, Weil - Dobke type)

To produce four-parameter TRV, several TRV control circuits have been developed but parallel current injection method with a Weil-Dobke TRV control circuit [9],[10] shown in Fig.6 is the most popular used synthetic testing circuit in the high power laboratories as it is capable of providing RRRV and recovery voltage as required by various standards. Weil-Dobke circuit has a low capacity requirement on the main capacitor bank as compared to other TRV control circuits and is easy to design the various circuit components. The circuit shown in Fig. 6 permits to produce 4 - parameters transient recovery voltages (TRV) according to IEC standards. The circuit consists of the following components: $\mathrm{V}_{\mathrm{C}}$ is the charging Voltage, $\mathrm{Cn}$ is the main capacitor bank, $\mathrm{C}_{1}$ and $\mathrm{C}_{2}$ are the TRV capacitor banks, $\mathrm{C}_{3}$ is the stray capacitor bank; $\mathrm{L}_{\mathrm{n}}, \mathrm{L}_{1}$ and $\mathrm{L} 2$ are the reactors; $\mathrm{R}_{1}$ and $\mathrm{R}_{2}$ are the resistors. The magnitude and the frequency of the transient recovery voltage depend up on the voltage to which the main capacitor $\mathrm{Cn}$ is charged and the values of circuit components. The circuit shown in Fig. 6 is also used in new synthetic test plant in ABB, Ludvika and it is proposed by A. K. Bystruev[10].

The optimized circuit components for the desired frequencies of $\mathrm{fn}_{1}$ and $\mathrm{fn}_{2}$ according to IEC standards for a particular rating of circuit-breaker can be determined by the proposed Program/Software developed by using MATLAB/Visual Basic 6. After finding optimal circuit components for a particular rating of circuit-breaker, design and simulation of 4-parameters TRV parallel current injection method synthetic testing circuit (Weil
Dobke type) is done by using PSIM simulator for testing Extra high voltage circuit breakers according to new TRV requirements given in IEC62271-100(2008). The circuit is designed and simulated for both terminal fault as well as short line fault test duty for testing $420 \mathrm{kV}$ and $800 \mathrm{kV}$ rating circuit-breakers. Design optimization is done to reduce the energy required by the capacitor banks and hence reduce the size and cost of capacitor banks also to save the space required.. The algorithm for the design and simulation of synthetic testing circuit for High Voltage circuit Breakers is shown in Fig.7.

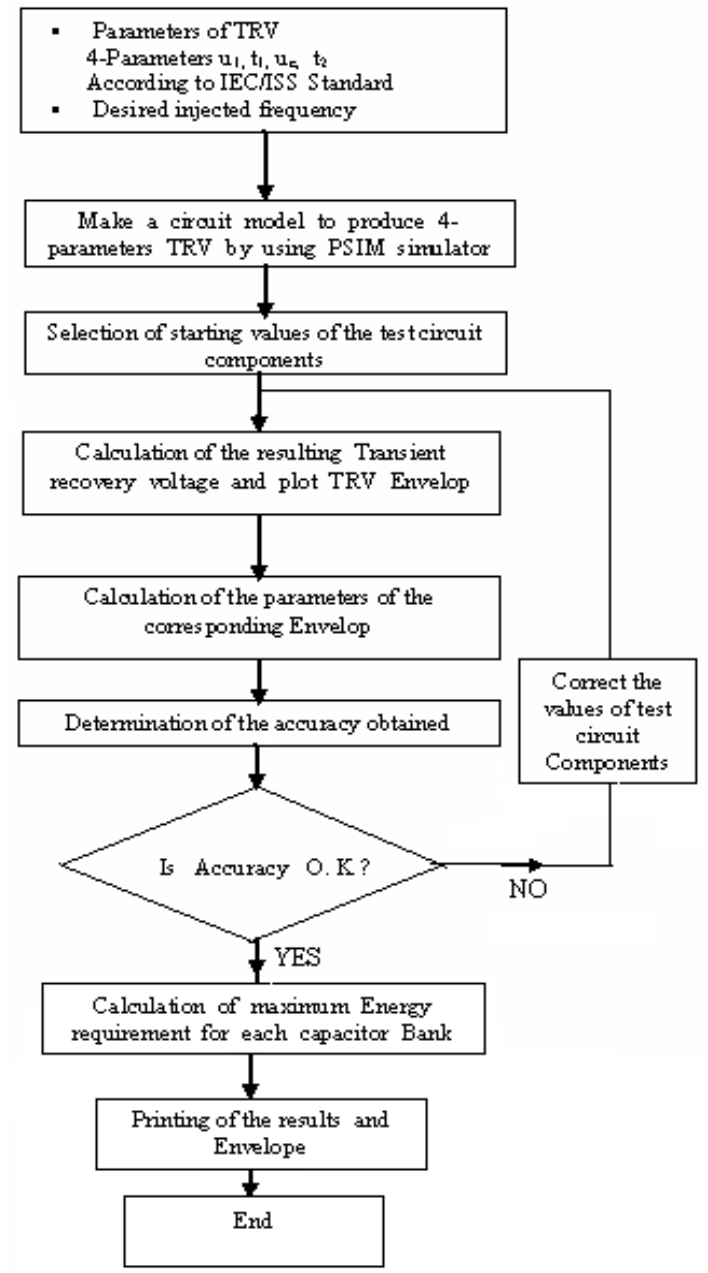

Fig.7. Algorithm for the design and simulation of synthetic testing circuits

The main capacitor $\mathrm{Cn}$ is charged to provide recovery voltage. The main capacitor $\mathrm{Cn}$ is charged to a peak value of recovery voltage as per the following equation (according to IEEE guide for synthetic testing of high voltage circuitbreakers).

$$
\mathrm{V}_{\mathrm{C}}=0.95 \times \mathrm{k}_{\mathrm{pp}} \mathrm{x} \sqrt{\frac{2}{3}} \mathrm{U}_{\mathrm{r}}
$$

Where $\mathrm{U}_{\mathrm{r}}=$ rated voltage of circuit-breaker

$\mathrm{k}_{\mathrm{pp}}=$ first-pole-to-clear factor

The TRV envelopes obtained for terminal as well as short-line fault duty conditions to test $420 \mathrm{kV}$ rating circuit-breakers are shown in Fig.8 to Fig.10. TRV Parameters obtained/realized from these envelopes are given in Table III. The expected TRV parameters as per IEC for testing $420 \mathrm{kV}$ rating circuit breakers for both terminal 
and short line fault test duty are given in Table II. Table I shows the optimal circuit components of TRV control circuit for testing $420 \mathrm{kV}$ rating CBs. Table IV shows the energy required by each capacitor bank and the total energy required for terminal fault test duty condition.

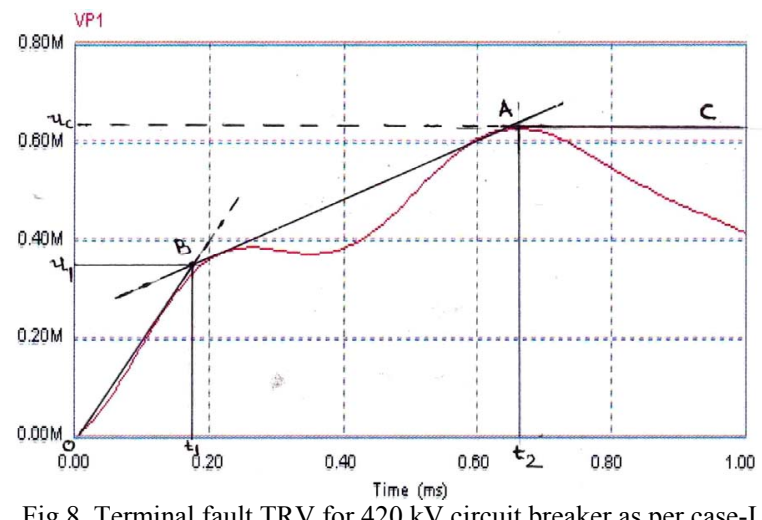

Fig.8. Terminal fault TRV for $420 \mathrm{kV}$ circuit breaker as per case-I (TRV curve represented in Fig.1 as per IEC)

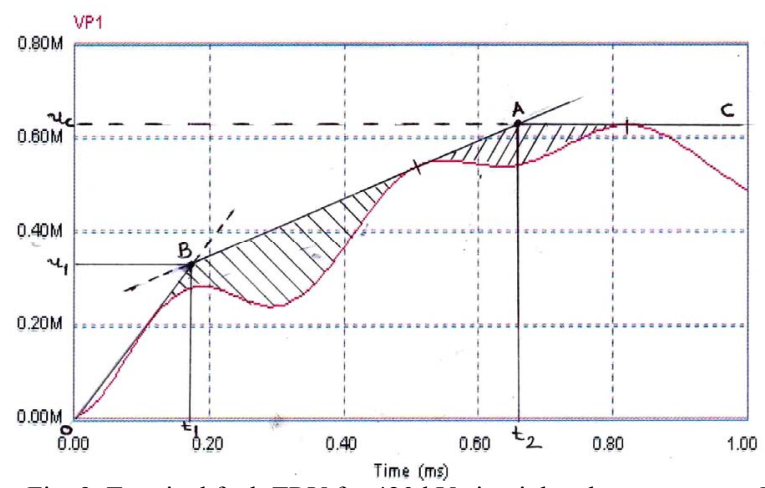

Fig. 9. Terminal fault TRV for $420 \mathrm{kV}$ circuit breaker as per case-II (TRV curve represented in Fig.2 as per IEC)

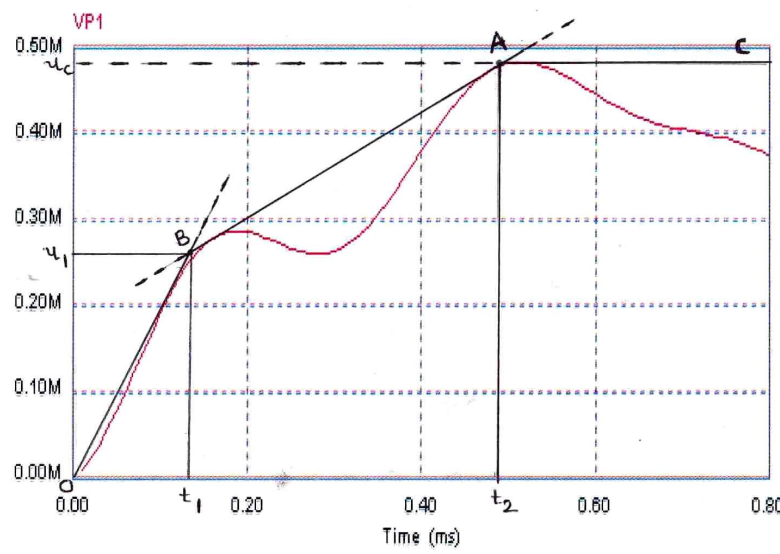

Fig.10. Short-line fault TRV for $420 \mathrm{kV}$ circuit breaker as per case-I (TRV curve represented in Fig. 1)

TABLEII

EXPECTED TKVPAR FOR 4 OKTT RATIHG CE

\begin{tabular}{|c|c|c|}
\hline THW Fa meters & $\begin{array}{l}\text { Tet Bnit: } \\
\text { Tamil }\end{array}$ & $\begin{array}{c}\text { Teting: } \\
\text { Shart Thuefinit }\end{array}$ \\
\hline 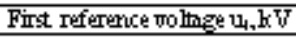 & 334 & 257 \\
\hline Time to resth $\eta_{1}, t_{1}$ & 167 & 12 \\
\hline 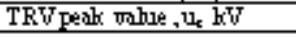 & 04 & $48 \pi$ \\
\hline Time to reachul $\mathrm{u}_{\mathrm{f}} \mathrm{t}$ & 66 & 516 \\
\hline Fate of rigen, & 2 & 2 \\
\hline
\end{tabular}

TAELEII

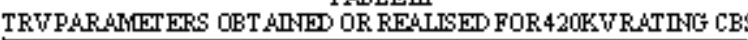

\begin{tabular}{|c|c|c|}
\hline THW Farmest & $\begin{array}{l}\text { Terding: } \\
\text { Temilifilt }\end{array}$ & $\begin{array}{l}\text { Ter fing: } \\
\text { Shout Fuefault }\end{array}$ \\
\hline 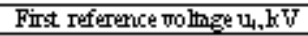 & 36 & 20 \\
\hline Time to renth $\eta_{1}, t_{1}$ & 169 & 130 \\
\hline 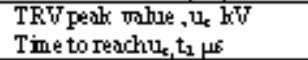 & 626 & $\begin{array}{l}48 \\
516\end{array}$ \\
\hline 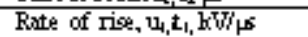 & 2 & 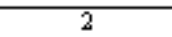 \\
\hline
\end{tabular}

TABLE IV

MaXimum Voltage ACROSS EACH CAPACITOR BANK AND ENERgY REQUIREMENT FOR EACH CAPACITOR BANK FOR TESTING $420 \mathrm{KV}$ CBS.

\begin{tabular}{|c|c|c|c|c|}
\hline Capacitor Banks & Value & $\begin{array}{c}\text { Max. } \\
\text { Voltage } \\
\text { across } \\
\text { cap. } \\
\text { Bank, } \\
\text { kV }\end{array}$ & $\begin{array}{l}\text { Energy } \\
\text { required } \\
\text { kJ }\end{array}$ & $\begin{array}{c}\text { Tota } \\
1 \\
\text { Ener } \\
\text { gy } \\
\text { reqd. } \\
\\
\text { MJ }\end{array}$ \\
\hline Main Capacitor Bank $C_{n}$ & $32 \mu \mathrm{F}$ & 424 & 2876.41 & \\
\hline TRV Capacitor Bank: $\mathrm{C}_{1}$ & $0.6 \mu \mathrm{F}$ & 623 & 116.43 & 3.38 \\
\hline $\mathrm{C}_{2}$ & $1.4 \mu \mathrm{F}$ & 744 & 387.47 & 5 \\
\hline Stray capacitor Bank: $\mathrm{C}_{3}$ & $21 \mathrm{nF}$ & 624 & 4.10 & \\
\hline
\end{tabular}

\section{GENERATION OF TRV ENVELOPES FOR} TESTING $800 \mathrm{KV}$ RATING CIRCUIT-BREAKERS

The TRV envelopes obtained for terminal as well as short-line fault duty conditions to test $800 \mathrm{kV}$ rating circuit-breakers are shown in Fig.11 to Fig.13. TRV Parameters obtained/realized from these envelopes are given in Table VI. The expected TRV parameters as per IEC for testing $800 \mathrm{kV}$ rating circuit breakers for both terminal and short line fault test duty are given in Table V. Table VII shows the energy required by each capacitor bank and the total energy required for terminal fault test duty condition for testing $800 \mathrm{kV}$ rating $\mathrm{CBs}$.

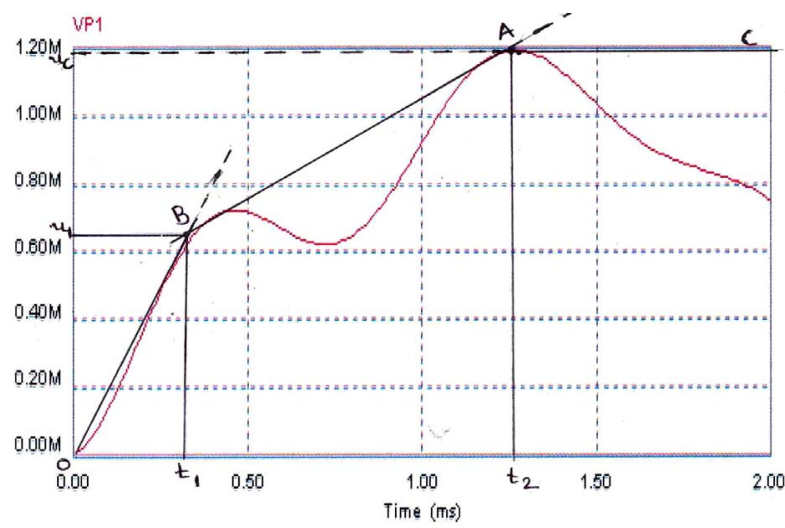

Fig.11. Terminal fault TRV for $800 \mathrm{kV}$ circuit breaker as per case-I (TRV curve represented in Fig.1 as per IEC)

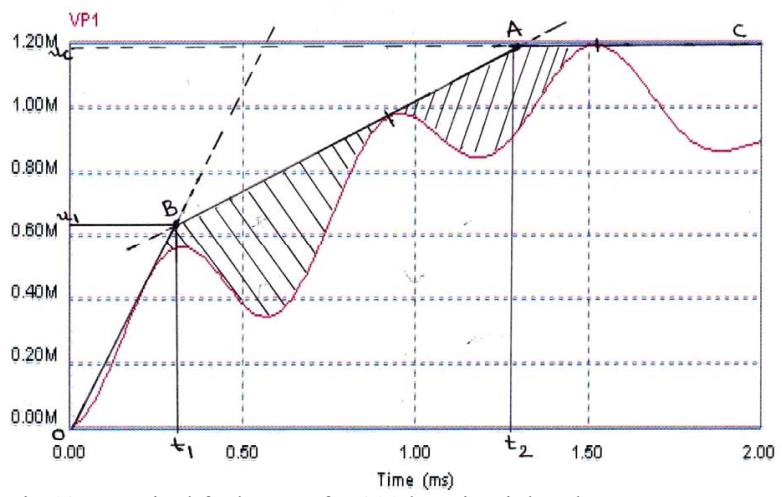

Fig. 12. Terminal fault TRV for $800 \mathrm{kV}$ circuit breaker as per case-II (TRV curve represented in Fig.2 as per IEC) 


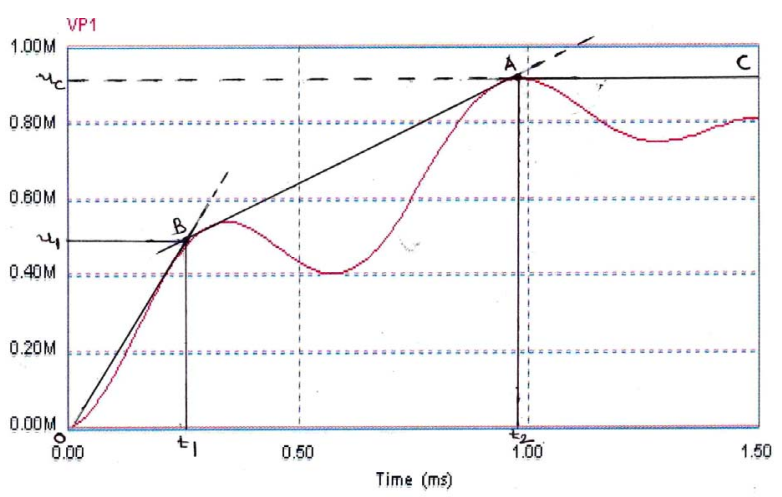

Fig.13. Short-line fault TRV for $800 \mathrm{kV}$ circuit breaker as per case-I (TRV curve represented in Fig. 1)

TABLE V

EXPECTED TRV PARAMETERS ACCORDING OF IEC FOR $800 \mathrm{KV}$ RATING CIRCUIT-BREAKERS

\begin{tabular}{|c|c|c|}
\hline TRV Parameters & $\begin{array}{c}\text { Test duty: } \\
\text { Terminal fault }\end{array}$ & $\begin{array}{c}\text { Test duty: } \\
\text { Short line fault }\end{array}$ \\
\hline First reference voltage $\mathrm{u}_{1}, \mathrm{kV}$ & 637 & 490 \\
\hline Time to reach $\mathrm{u}_{1}, \mathrm{t}_{1} \mu \mathrm{s}$ & 318 & 245 \\
\hline TRV peak value, $\mathrm{u}_{\mathrm{c}} \mathrm{kV}$ & 1189 & 914 \\
\hline Time to reach $\mathrm{u}_{\mathrm{c},} \mathrm{t}_{2} \mu \mathrm{s}$ & 1272 & 980 \\
\hline Rate of rise, $\mathrm{u}_{1, \mathrm{t}}, \mathrm{t}, \mathrm{kV} / \mu \mathrm{s}$ & 2 & 2 \\
\hline
\end{tabular}

TABLE VI

TRV PARAMETERS OBTAINED FOR $800 \mathrm{KV}$ RATING CIRCUIT-BREAKERS

\begin{tabular}{|c|c|c|}
\hline TRV Parameters & $\begin{array}{c}\text { Test duty: } \\
\text { Terminal fault }\end{array}$ & $\begin{array}{c}\text { Test duty: } \\
\text { Short line fault }\end{array}$ \\
\hline First reference voltage $\mathrm{u}_{1}, \mathrm{kV}$ & 640 & 486 \\
\hline Time to reach $\mathrm{u}_{1}, \mathrm{t}_{1} \mu \mathrm{s}$ & 318 & 244 \\
\hline TRV peak value, $\mathrm{u}_{\mathrm{c}} \mathrm{kV}$ & 1189 & 913 \\
\hline Time to reach $\mathrm{u}_{\mathrm{c},} \mathrm{t}_{2} \mu \mathrm{s}$ & 1270 & 980 \\
\hline Rate of rise, $\mathrm{u}_{1, \mathrm{t}}, \mathrm{kV} / \mu \mathrm{s}$ & 2.01 & 1.99 \\
\hline
\end{tabular}

TABLE VII

MAXIMUM Voltage ACROSS EACH CAPACITOR BANK AND ENERGY REQUIREMENT FOR EACH CAPACITOR BANK FOR TESTING 800KV CBS

\begin{tabular}{|c|c|c|c|c|}
\hline Capacitor Banks & Value & $\begin{array}{c}\text { Max. } \\
\text { Voltage } \\
\text { across } \\
\text { capacito } \\
\text { r Bank, } \\
\text { kV }\end{array}$ & $\begin{array}{c}\text { Energy } \\
\text { required } \\
\mathrm{kJ}\end{array}$ & $\begin{array}{c}\text { Total } \\
\text { Energ } \\
\text { y } \\
\text { reqd. } \\
\text { MJ }\end{array}$ \\
\hline $\begin{array}{l}\text { Main Capacitor Bank: } C_{n} \\
\text { TRV Capacitor Bank: } C_{1} \\
C_{2} \\
\text { Stray capacitor Bank: } C_{3}\end{array}$ & $\begin{array}{c}36 \mu \mathrm{F} \\
0.85 \mu \mathrm{F} \\
2.2 \mu \mathrm{F} \\
21 \mathrm{nF}\end{array}$ & $\begin{array}{c}807 \\
1185 \\
1435 \\
1189\end{array}$ & $\begin{array}{c}11722.4 \\
596.80 \\
2265.14 \\
14.85\end{array}$ & 14.60 \\
\hline
\end{tabular}

\section{CONCLUSION}

The parameters of TRV defined by IEC standards are quite impossible to analytically link with the values of the components of the test circuit. So computer aided design and simulation of synthetic testing circuits (TRV shaping circuits) is first necessary in order to determine the parameters of the TRV corresponding to a given test circuit.

The objective was to design and simulate 4Parameters TRV synthetic testing circuit used to generate TRV envelopes for testing Extra high voltage circuit breakers according to new TRV requirements given in IEC 62271-100 (2008). A 4-parameter TRV synthetic test circuit based on parallel current injection method is designed and simulated for both Terminal as well as Short line faults test duty for testing $420 \mathrm{kV}$ and $800 \mathrm{kV}$ rating circuit-breakers. Design optimization is also done to reduce the energy required by the capacitor banks and hence reduce the size and cost of capacitor banks also to save the space required.

The results obtained by using synthetic test circuit has been discussed and compared with the required results according to IEC standards. The results shown are almost the same according to IEC standards.

\section{REFERENCES}

[1] IEC 62271-100 (2008): High voltage Alternating Current CBs.

[2] IEC 62271-101 (2006): Synthetic Testing of High Voltage Alternating Current Circuit Breakers.

[3] IEEE Standard PC37.04b (2008), " IEEE standard rating structure for AC High Voltage circuit breakers rated on a symmetrical current basis"- Amendment to change the description of TRV for harmonization with IEC 62271-100.

[4] Ruben D. Garzon, High Voltage Circuit Breakers - Design, Testing and Applications, Marcel Dekker, New York, 2002.

[5] B. Ravindranath and M. Chander, Power system protection and switchgear, Wiley Eastern, New Delhi, 2007

[6] Rudra Pratab, Mat lab 7, Oxford University Press, New Delhi, 2006

[7] S. S. Rao, Optimization: Theory and Applications, New Age International, New Delhi, 2007.

[8] C.L.Wagner, H.M.Smith, "Analysis of transient recovery voltage (TRV) rating concepts", IEEE transactions on Power Apparatus and Systems Vol. PAS - 103, 1984, P. 3354.

[9] W.P. Legros, A.M.Genon, "Computer aided design of synthetic test circuit for high voltage circuit breakers", IEEE transactions on power delivery, Vol. 4, No.2, April 1989.

[10] B. L. Sheng, "Design consideration of Weil - Dobke synthetic testing circuit for the interrupting testing of $\mathrm{HV} \mathrm{AC}$ circuit breakers," in proc. 2001 IEEE Power Engineering Society Conference, pp. 295 - 299.

[11] B.L. Sheng and L. Van der sluis, "The influence of the arc voltage in synthetic test circuits" IEEE Trans. on power delivery, Vol. 10, No. 1, January 1995.

[12] B.L. Sheng and L. Van der, "Comparison of synthetic test circuits for ultra high voltage circuit breakers", IEEE Trans. on power delivery, Vol. 11, No. 4, Oct. 1996.

[13] B. L. Sheng and L. Van der, "A new synthetic test circuit for Ultra-high voltage circuit breakers," IEEE Trans. on Power Delivery, vol. 12, No. 4, pp.1514-1519, Oct.1997.

[14] L. Van der and W.R.Rutgers, "comparison of test circuits for high voltage circuit breakers by numerical calculations with arc models" IEEE Trans. on power delivery, Vol.7,No.4, oct.1992.

[15] PSIM Simulation Software, Version 6.1, Powersim Inc. Feb.2005 